\title{
High strength epoxy system modified with soft block copolymer and stiff core-shell rubber nanoparticles: Morphology, mechanical properties, and fracture mechanisms
}

\author{
A. Bajpai*, B. Wetzel, K. Friedrich \\ Institut für Verbundwerkstoffe GmbH (IVW), Technische Universität Kaiserslautern (TUK), Erwin-Schrödinger-Str. 58, \\ 67663 Kaiserslautern, Germany
}

Received 2 September 2019; accepted in revised form 14 November 2019

\begin{abstract}
The tensile and thermo-mechanical properties, as well as the fracture mechanical behavior of a high strength epoxy/amine system modified with particulates of a block copolymer (BCP), a core shell rubber (CSR) and a mixture of them, were investigated at $23{ }^{\circ} \mathrm{C}$. The results show that the fracture energy was increased by more than $700 \%$ with a filler content of $12 \mathrm{wt} \% \mathrm{BCP}$ and by more than $600 \%$ with a filler content of $12 \mathrm{wt} \% \mathrm{CSR}$ particles. The content of BCP and CSR particles influences the final morphology and, thus, also the tensile properties, fracture toughness and thermo-mechanical behavior of the modified systems. The toughening mechanisms induced by the BCP and CSR particles were identified as (a) localized plastic shear yielding around the particles and (b) cavitation of the particles followed by plastic void growth of the epoxy polymer. The fracture toughness and fracture energy were co-related to the plastic zone size for all systems modified. These mechanisms were modeled using the Hsieh et al. [45] approach which also allows calculating the values of $G_{\text {Ic }}$ of the differently modified polymers. Excellent agreement was found between the predictions and the experimentally measured fracture energies.
\end{abstract}

Keywords: nanocomposites, thermosetting resin, mechanical properties

\section{Introduction}

Epoxies are commonly used as a matrix in a wide range of aerospace applications, electronics, and various diverse industrial applications. Their excellent electrical and chemical properties, high strength, low shrinkage, and low absorption of moisture make them the most used matrix system. Besides incredible mechanical and thermal properties, the highly crosslinked [1] microstructure makes, however, an unmodified epoxy system brittle, resulting also in poor resistance to crack initiation and propagation. As a consequence, epoxies must usually be toughened by the addition of a second component. Various approaches were followed by researchers to toughen brittle epoxy-based systems e.g. the use of chemical modifications that involve chain extenders or plasticizers. The second most common method is introduction of a second phase i.e. liquid rubber. The different types of rubber modifiers that have been in practice so far are a carboxyl-terminated copolymer of butadiene and acrylonitrile (CTBN) [2] or an amine-terminated copolymer of butadiene and acrylonitrile (ATBN) [3]. Rezaifard et al. [4] have used poly(methyl methacrylate) (PMMA) grafted natural rubber instead of CTBN for toughening of epoxy, resulting in an improved adhesive joint failure strength 
by controlling the resin solubility parameter. The addition of thermoplastics to epoxy has been reported by several researchers, and this approach is recognized as an alternative to rubber toughening to improve the toughness of brittle epoxy networks. Thermoplastics such as poly(phenylene oxide) (PPO) [5], poly(ether imide) (PEI) [6], poly(ether ether ketone) (PEEK) [7] and poly(ether sulphone) (PES) [8] were added to epoxies in order to tailor the fracture properties of the whole system without reducing the glass transition temperature. Thermoplastics were either dispersed in the epoxy by reaction-induced phase separation $[9,10]$ or by the suspension of pre-formed particles. Studies show that morphologies of these systems have a direct influence on the properties of the modified systems [11]. While in some cases, satisfactory results have been achieved, in other cases the thermoplastic toughening agents did not bring significant improvement in fracture toughness, and in some cases even a decrease due to poor filler-matrix adhesion [12]. Further, epoxy-thermoplastic systems are also associated with processing problems, which is due to poor compatibility between the uncured epoxy resin and the thermoplastic toughening phase [13]. The pre-formed elastomeric particles also belong to the category of rubber-modified epoxies, in which the particles are formed by a rubber core surrounded by a thin glassy shell, not allowing the rubber particles to agglomerate. They are also called core-shell rubber particles (CSR). Poly-butadiene, poly-butyl (acrylate), poly-styrene butadiene or polysiloxane are used for the core material and PMMA as the commonly used shell material. Giannakopoulos et al. [14] have modified epoxy resin by the addition of pre-formed core-shell rubber particles of a size of 100 to $300 \mathrm{~nm}$ in diameter, whereby the glass transition temperature $T_{\mathrm{g}}$ of the epoxy used remained unchanged even after curing; however a significant decrease in Young's modulus and tensile strength took place. The fracture energy was also increased from 77 to $840 \mathrm{~J} / \mathrm{m}^{2}$ for the epoxy with $15 \mathrm{wt} \%$ of the $100 \mathrm{~nm}$ diameter CSR particles.

Block copolymers (BCP) have gained importance as the latest type of rubbery modifiers used for toughening epoxy polymers. Barsotti [15] compared the fracture toughness improvement ability of block copolymer and CTBN in the same epoxy system but using another block copolymer poly(methyl methacrylate)- $b$-poly(butyl acrylate)- $b$-poly(methyl methacrylate) (MAM). They reported that, for the same wt $\%$ loading, MAM modified epoxies have a significantly higher fracture toughness than the CTBN modified epoxies. They also stated that a dicyandiamide (DICY) cured DGEBA epoxy, $5 \mathrm{wt} \%$ MAM modifier gave a value of $K_{\mathrm{Ic}}=1.64 \mathrm{MPa} \cdot \mathrm{m}^{1 / 2}$ while a value of $K_{\mathrm{Ic}}=1.32 \mathrm{MPa} \cdot \mathrm{m}^{1 / 2}$ was measured for a $5 \mathrm{wt} \%$ CTBN modifier. Pearson et al. [16] compared the fracture toughness improvement ability of SBM block copolymer, core-shell rubber particles and CTBN rubber on lightly cross-linked piperidine cured epoxy. These researchers found that the SBM block copolymers could continuously toughen the epoxies up to $25 \mathrm{wt} \%$ of the SBM, while a plateau or a peak of fracture toughness was observed at about $10 \mathrm{wt} \%$ for the core-shell rubber particle or CTBN modified epoxies. More importantly, the maximum value of $K_{\text {Ic }}$ for the SBM modified epoxies was reported to nearly approach $5 \mathrm{MPa} \cdot \mathrm{m}^{1 / 2}$, while the core-shell rubber particle or CTBN modified epoxies reached a plateau or maximum at about $3 \mathrm{MPa} \cdot \mathrm{m}^{1 / 2}$. The results from the previous studies have demonstrated that block copolymer toughening has the potential to provide a higher toughness improvement compared to traditional homopolymers and random copolymer toughening agents. But the main problem involved in the addition of $\mathrm{BCP}$ is that they can reduce all other properties like elastic modulus, tensile strength, and $T_{\mathrm{g}}[17,18]$.

Adding rigid particles can improve the strength and modulus of epoxy nanocomposites while increasing also its fracture toughness, and without decreasing the glass transition temperature. Many authors have studied the use of rigid particles such as titanium dioxide $\left(\mathrm{TiO}_{2}\right)$ [19], alumina $\left(\mathrm{Al}_{2} \mathrm{O}_{3}\right)$ [20], silica $\left(\mathrm{SiO}_{2}\right)$ [21] and glass [22]. Though the rubber toughened epoxy system gained prominence for the improvement of the impact properties of cured epoxy, there is a significant decrease in the modulus and thermal stability of the materials an and increasing tendency to absorb water with an adjacent loss of properties at elevated temperatures. So, the search for alternative toughening methods led to discover a new method using two different types of fillers simultaneously. While one will increase the fracture toughness, the other may increase at the same time the modulus and glass transition temperature or at least hinder them from decreasing. Such a type of approach is known as hybrid toughening, and this was first adapted by Maxwell et al. [23] who tried to restore the lost stiffness caused by the application 
of rubber modification. Since then, several researchers have started examining many combinations of different sized particles for hybrid toughening. The following systems were examined by different researchers, e.g. $\mathrm{SiO}_{2}$ and CSR [24, 25], $\mathrm{BCP}$, and $\mathrm{TiO}_{2}$ nanoparticles [19] and CTBN-rubber and CNT [26, 27]. However, no synergies were observed in the case of BCP-CNT hybrids [28]. Recently some researchers reported hybrid toughening of $\mathrm{BCP}$ and CSR nanoparticles [29, 30].

In the present work block co-polymer and core-shell rubber particles with a stiff core were used to toughen a high strength amine cured epoxy system. The mechanical properties and fracture energies of $\mathrm{BCP}$, CSR and BCP/CSR hybrid toughened epoxy systems were quantified. Also, the thermal-mechanical behavior and structure-property relationship of the modified epoxy systems were determined. Further, the toughening mechanisms involved were identified, and existing analytical models were used to predict the elastic modulus and fracture energy.

\section{Materials}

In the present work, EPONTM Resin 862 ( ), the diglycidyl ether of bisphenol $\mathrm{F}$, was used [31], having an epoxy equivalent weight (EEW) of $169 \mathrm{~g} \cdot \mathrm{eq}^{-1}$ supplied by Hexion Inc. It was mixed with LME10169 developmental epoxy resin supplied by Huntsman Corporation, having an EEW of $250 \mathrm{~g} \cdot \mathrm{eq}^{-1}$, is a difunctional epoxy resin, with a bulky backbone showing structural rigidity with high aromatic content [32]. The mixing ratio of EP and LME10169 amounted to 93:7 and can be considered as the base matrix (MEP). The curing agent, Ethacure100 $(\mathbf{H})$ was an aromatic amine-based curing agent which contains 3,5-diethyltoluene-2,4-diamine (75-81\%) and 3,5-diethyltoluene-2,6-diamine (18-24\%) was supplied by Albemarle $\mathrm{GmbH}$, Germany.

A poly[(methyl)methacrylate-co-polar comonomer] -b-poly(butyl acrylate) MAM functional block copolymer (trade name D51N) supplied as powder by Arkema, France, was used as the toughening agent. The CSR nanoparticles used in this work were Kane Ace MX170 supplied by Kaneka, Belgium. The material was supplied in the form of a masterbatch with a $25 \mathrm{wt} \%$ concentrate of core-shell rubber toughening agent in unmodified liquid epoxy resin based on bisphenol A. The specific gravity amounted to $1.1 \mathrm{~g} / \mathrm{cm}^{3}$ and the nominal viscosity @ $50{ }^{\circ} \mathrm{C}$ was $12000 \mathrm{mPa} \cdot \mathrm{s}$ [33].
Before completing the final MEP/BCP-systems, a BCP-masterbatch with a concentration of $25 \mathrm{wt} \%$ was prepared. The corresponding amount of modifier was added to the resin and mixed with a dissolver aggregate (Dispermat, VMA Getzmann $\mathrm{GmbH}$ ), then heated up to $100^{\circ} \mathrm{C}$ until a homogenous solution was reached and optical transparency observed. For curing the MEP/BCP samples, the $\mathrm{BCP}$-masterbatch was diluted with neat resin at $50^{\circ} \mathrm{C}$ to the targeted concentration, and then a stoichiometric amount of curing agent was added. This mixture was stirred for $20 \mathrm{~min}$. Finally, the reactive system was cast into glass molds, which were coated with a PAT-607/FB (E. und P. Würtz GmbH \& Co $\mathrm{KG}$, Germany) release agent. The samples were then cured using a three-step curing cycle: (1) $80^{\circ} \mathrm{C}$ for $4 \mathrm{~h},(2) 105^{\circ} \mathrm{C}$ for $4 \mathrm{~h}$, and (3) $120^{\circ} \mathrm{C}$ for $18 \mathrm{~h}$. The CSR-systems were manufactured in the same way as the block copolymer systems. For preparing the hybrids, an appropriate amount of CSR-masterbatch and BCP-masterbatch was added to the neat resin and then stirred at $60^{\circ} \mathrm{C}$ for $30 \mathrm{~min}$ to ensure a homogenous mixture of the components. After the system was cooled down to $50^{\circ} \mathrm{C}$, a stoichiometric amount of curing agent was added. Series of three types of systems were prepared accordingly: (1) the BCP toughened systems, with varying concentrations between 2 and $12 \mathrm{wt} \%$, (2) the CSR modified systems with varying concentrations between 2 and $12 \mathrm{wt} \%$, and (3) hybridized systems thereof, containing equal $\mathrm{wt} \%$ of $\mathrm{BCP} / \mathrm{CSR}(1 / 1,2 / 2$ and $3 / 3)$.

\section{Experimental methods}

A Mettler-Toledo system DSC1 STAR ${ }^{\circledR}$ was used to determine the thermal quantities. Firstly, the cured sample material was weighed $(\sim 7-13 \mathrm{mg})$ and placed in a crucible, sealed with lids with the help of a crucible sealing press. In the first cycle, the sample was heated from room temperature up to $200^{\circ} \mathrm{C}$ and cooled down to room temperature and again heated to $200^{\circ} \mathrm{C}$ with a heating rate of $10^{\circ} \mathrm{C} / \mathrm{min}$. In the present study, the storage moduli, the loss moduli, and the $\tan \delta$ values of all the bulk samples were measured by dynamic mechanical thermal analysis. A Q800 V7.5 Build 127 DMTA machine from TA Instruments, operating in 3-point bending mode at $1 \mathrm{~Hz}$, was used to characterize specimens of $60 \mathrm{~mm} \times 10 \mathrm{~mm} \times 4 \mathrm{~mm}$ in size. The glass transition temperature $T_{\mathrm{g}}$ of the bulk epoxy samples was determined by the peak value of $\tan \delta$. The temperature 
range was set from -120 to $200^{\circ} \mathrm{C}$ with a heating rate of $2{ }^{\circ} \mathrm{C} / \mathrm{min}$. Plane strain compression (PSC) tests were conducted to determine the yield stress and failure strain according to standard DIN EN ISO 604. The tests were performed on a universal testing machine (Zwick 1474, Zwick Roell AG, Ulm, Germany) in compression configuration with a constant strain rate of $2 \mathrm{~mm} / \mathrm{min}$ and a temperature of $23^{\circ} \mathrm{C}$. Before testing, the samples were cut with a microtome to ensure parallel and smooth surfaces. Tensile tests were conducted at $23^{\circ} \mathrm{C}$ on a universal testing machine (Zwick 1474, Zwick Roell AG, Ulm, Germany) in a tensile configuration according to standard DIN EN ISO 527-2, using dog-bone shaped (ISO 572-2 type 1B) samples. The testing speed was chosen to be $2 \mathrm{~mm} / \mathrm{min}$, whereby a $10 \mathrm{kN}$ load cell and a precision sensor-arm extensometer for determining the specimen strain were used. The plane strain fracture toughness $\left(K_{\text {Ic }}\right)$ of the materials was measured experimentally in a universal testing machine (Zwick 1474, Zwick Roell AG, Ulm, Germany) at $23^{\circ} \mathrm{C}$ by using compact tension (Figure 1) samples under tensile loading conditions (according to the standard ISO 13586) and at a strain rate of $0.2 \mathrm{~mm} / \mathrm{min}$. The thickness $B$ and the width $W$ of the specimens were chosen to be 6 and $36 \mathrm{~mm}$, respectively. Before testing, a notch was machined and then sharpened by tapping a fresh razor blade [34] into the material, so that a sharp crack was initiated with a length $a_{0}(0.45 \mathrm{~W} \leq$ $a_{0} \leq 0.55 \mathrm{~W}$ ). The fracture toughness $K_{\text {Ic }}$ was then calculated by Equation (1), where $F$ is the maximum force observed in the load-displacement curve and ao is the initial crack length for calculating $\alpha=a_{0} / W$ and $f\left(a_{0} / W\right)$ as shown in Equations (1) and (2) [17]:

$K_{\mathrm{Ic}}=\frac{F}{B \sqrt{W}} \cdot f\left(\frac{a_{0}}{W}\right)$

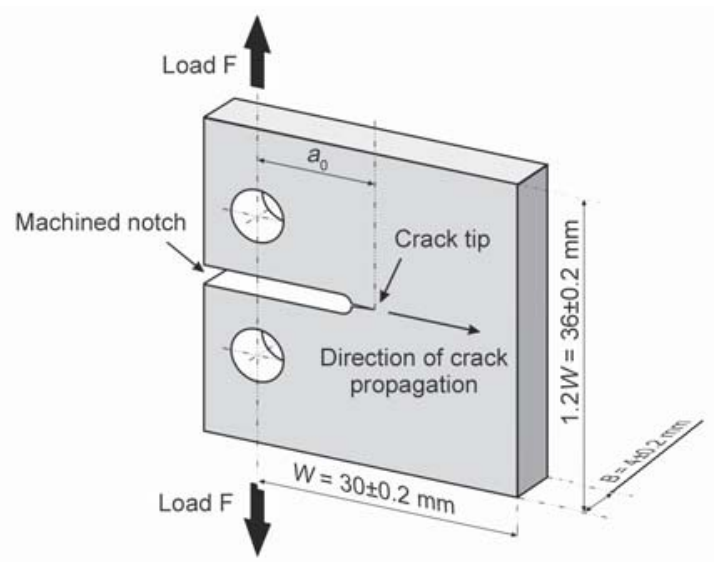

Figure 1. Compact tension sample geometry used for fracture toughness measurement.

The knowledge of the critical stress intensity factor $K_{\text {Ic }}$, the elastic modulus $E_{\mathrm{t}}$ and Poisson's ratio $v$ $(\sim 0.35)$ [18] allows calculating the critical energy release rate $G_{\text {Ic }}$ defined in Equation (3):

$G_{\mathrm{Ic}}=\frac{K_{\mathrm{Ic}}^{2}\left(1-v^{2}\right)}{E_{\mathrm{t}}}$

The fractured surfaces of the CT tested nanocomposites were studied with the help of a field emission scanning electron microscope (SEM SUPRA ${ }^{\text {TM }} 40$ VP, Carl Zeiss NTS GmbH, Oberkochen, Germany). Before scanning, the surfaces of the samples were sputtered with a thin layer of gold and platinum for $70 \mathrm{sec}$ using a sputtering device (SCD-050, Oerlikon Balzers, Bingen, Germany). A white light profilometer (FRT MicroProf, FRT GmbH, Bergisch Gladbach, Germany) was employed to measure the surface roughness of fractured compact tension samples in non-contact mode. It has a lateral resolution of $1 \mu \mathrm{m}$, the vertical resolution of $3 \mathrm{~nm}, x / y$ scan range: $100 \mathrm{~mm} \times 100 \mathrm{~mm}$, and $z$-scan range: $3 \mathrm{~mm}$.

$f\left(\frac{a_{0}}{W}\right)=f(\alpha)=\frac{2+\alpha}{(1-\alpha)^{3 / 2}}\left(0,866+4,64 \alpha-13,32 \alpha^{2}+14,72 \alpha^{3}-5,60 \alpha^{4}\right)$

Table 1. Glass transition temperature, $T_{\mathrm{g}}$ of amine cured unmodified epoxy system and amine cured epoxy system modified with $\mathrm{BCP}$ and CSR.

\begin{tabular}{|l|c|c|l|c|c|l|c|c|}
\hline \multicolumn{1}{|c|}{ System } & $\begin{array}{c}\boldsymbol{T}_{\mathrm{g}} \mathbf{D S C} \\
{\left[{ }^{\circ} \mathbf{C}\right]}\end{array}$ & $\begin{array}{c}\boldsymbol{T}_{\mathrm{g}}[\mathbf{t a n} \boldsymbol{\delta}] \\
{\left[{ }^{\circ} \mathbf{C}\right]}\end{array}$ & \multicolumn{1}{|c|}{ System } & $\begin{array}{c}\boldsymbol{T}_{\mathrm{g}} \mathbf{D S C} \\
{\left[{ }^{\circ} \mathbf{C}\right]}\end{array}$ & $\begin{array}{c}\boldsymbol{T}_{\mathrm{g}}[\tan \boldsymbol{\delta}] \\
{\left[{ }^{\circ} \mathbf{C}\right]}\end{array}$ & \multicolumn{1}{|c|}{ System } & $\begin{array}{c}\boldsymbol{T}_{\mathrm{g}} \mathbf{D S C} \\
{\left[{ }^{\circ} \mathbf{C}\right]}\end{array}$ & $\begin{array}{c}\boldsymbol{T}_{\mathrm{g}}[\tan \boldsymbol{\delta}] \\
{\left[{ }^{\circ} \mathbf{C}\right]}\end{array}$ \\
\hline MEP_H & 134 & 139 & MEP_2CSR & 136 & $\mathrm{n} / \mathrm{a}$ & MEP_12BCP & 134 & 138 \\
\hline MEP_2BCP & 134 & $\mathrm{n} / \mathrm{a}$ & MEP_4CSR & 136 & 146 & MEP_2BCP_2CSR & 135 & 138 \\
\hline MEP_4BCP & 135 & 140 & MEP_6CSR & 134 & $\mathrm{n} / \mathrm{a}$ & MEP_1BCP_1CSR & 136 & 146 \\
\hline MEP_6BCP & 136 & n/a & MEP_8CSR & 140 & 146 & MEP_3BCP_3CSR & 138 & 146 \\
\hline MEP_8BCP & 136 & 138 & MEP_10CSR & 138 & n/a & & & \\
\hline MEP_10BCP & 136 & n/a & MEP_12CSR & 143 & 146 & & & \\
\hline
\end{tabular}




\section{Results and discussion}

\subsection{Glass transition and viscoelastic properties}

The glass transition temperature $T_{\mathrm{g}}$ of amine-cured unmodified and BCP, CSR, and hybrid modified systems were measured with the help DSC and DMTA techniques. The results were tabulated as shown in Table 1. It was observed that for the MEP system, the $T_{\mathrm{g}}$ was measured as $134^{\circ} \mathrm{C}$ by DSC. The addition of block copolymers does not influence the $T_{\mathrm{g}}$ of the modified systems which was confirmed by other researchers as well [35-37]. The main $\alpha$ relaxation was found at around $139^{\circ} \mathrm{C}$ (Figures $2 \mathrm{a}, 2 \mathrm{~b}$ ), which
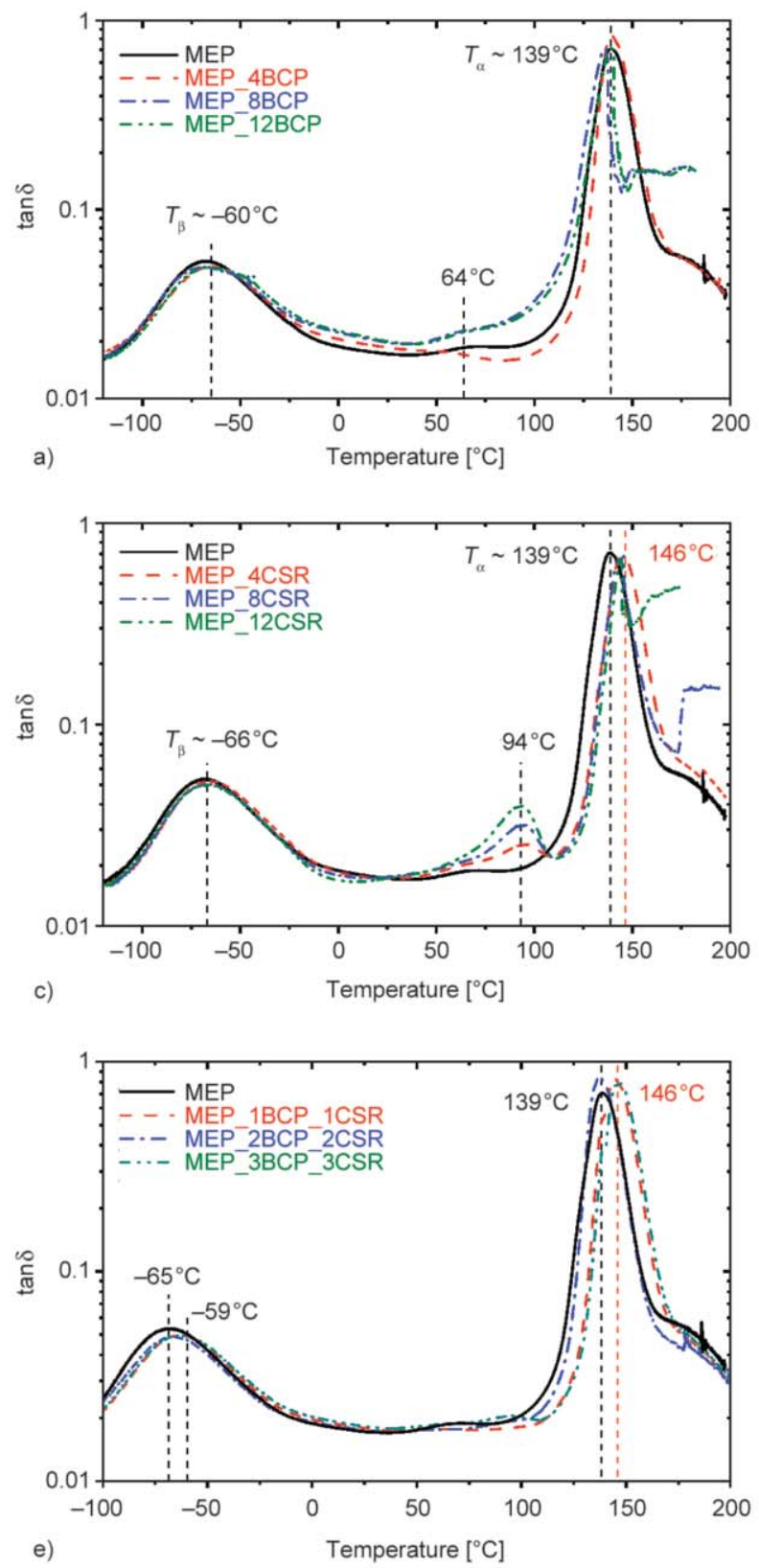

was associated with the glass transition temperature of the epoxy-rich phase, where larger segments of the polymer become mobile. A $\beta$-transition peak $\left(T_{\beta}\right)$ was observed at $-66^{\circ} \mathrm{C}$. The $\beta$ relaxation of epoxy results from molecular motions of the epoxy network. The addition of BCP was found to have no effect on the $\beta$ relaxation of the epoxy, however, for all the modified systems a dip is observed in the $\beta$-transition peak because of the plasticization effect caused by the PbuA blocks incorporation in the epoxy. Small shoulders (at $64^{\circ} \mathrm{C}$ ) were observed next to the main $\alpha$ relaxation of the epoxies on the $\tan \delta$ curves of the BCP modified epoxies, but a similar shoulder
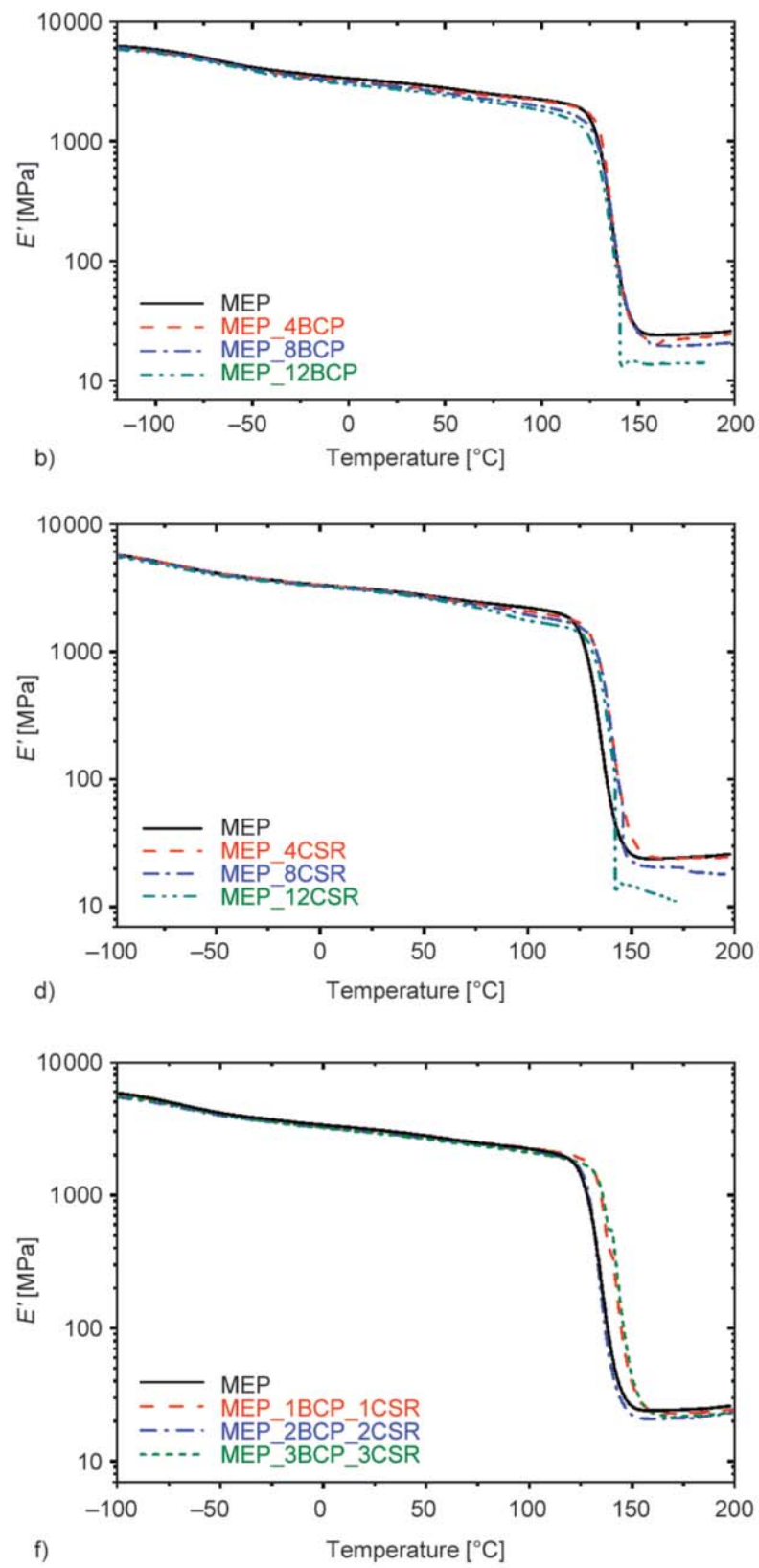

Figure 2. Graphs showing damping factor $(\tan \delta)$ and storage modulus $\left(E^{\prime}\right)$ with respect to temperature, for different modified epoxy systems. (a, b) MEP_BCP system, (c, d) MEP_CSR system and (e, f) MEP_BCP_CSR system. 
was not observed in the $\tan \delta$ curve of the unmodified epoxy. These shoulders may be representing presence of some random block copolymer or may be caused by the combination of PbuA and PMMA blocks. A micro-phase separation was also observed for all compositions modified with CSR nanoparticles. This was evident from the small shoulders at $94{ }^{\circ} \mathrm{C}$ which represent the glass transition temperature of the core present in the CSR particle, see Figures 2c, 2d. The peak's height does not change considerably with the incorporation of CSR particles, which explains that the damping factor remains almost the same for all $\mathrm{wt} \%$ of CSR, however a shift in the peak was observed towards higher temperature, which indicates a rise in the glass transition temperature due to the addition of bisphenol-A resin from the CSR masterbatch. For hybrid nanocomposites, the stiff CSR particles suppress the microphase separation of block copolymers, providing lower and broader peaks of the $\tan \delta$ curve as compared to the epoxy/CSR and epoxy/ BCP modified systems for the same composition alone (Figures 2e, 2f).

\subsection{Compressive properties}

The addition of BCP and CSR particles reduces the compressive true yield stress due to the soft nature of the modifiers. The representative compressive true stress-strain curves of the unmodified and the modified epoxy systems with different $\mathrm{wt} \%$ of modifiers are shown in Figure 3. The compressive modulus of the unmodified epoxy system was measured as $2020 \mathrm{MPa}$ which was lower than its tensile modulus due to the frictional effects and compliance corrections from the plane compression test [38]. Three different stages of deformation were observed on the representative true stress-strain curve obtained from PSC. An initial linear elastic region up to the yield

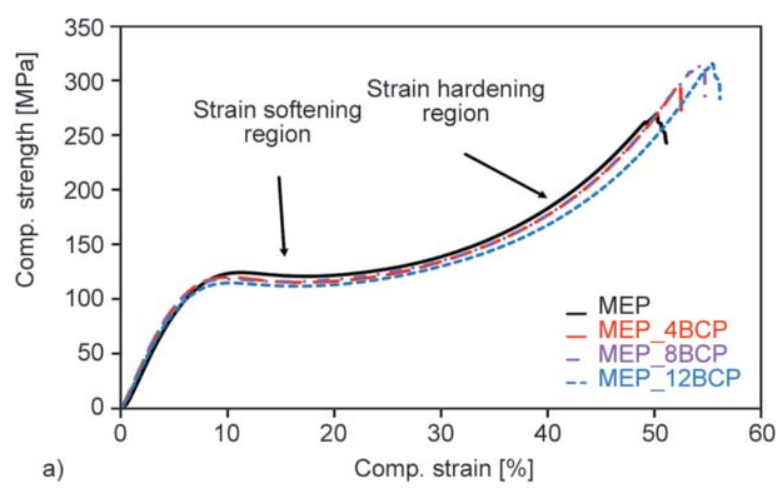

point was followed by a strain-softening region where the stress nearly remains on a plateau with increasing strain. The latter can be also considered as a necessary phenomenon for localized shear banding [39]. Further increasing the strain results in strain hardening where stress increases swiftly until the material breaks. In BCP modified systems, on the one hand, the yield stress and the strain-softening becomes flatter with increasing $\mathrm{BCP} w \mathrm{t} \%$. To support this theory, researchers $[35,40]$ performed cross-polarized images of the cross-section of PSC test samples that were loaded up to their strain-softening limit. The CSR modified epoxies, on the other hand, showed very slight changes in strain-softening and shear yielding behavior (Figure $3 b$ ). The fracture strengths of the modified systems did not show any clear trend with increasing BCP or CSR concentration because fracture was highly sensitive to defects present within and on the surface of the samples [40].

\subsection{Tensile properties}

The tensile properties such as tensile strength $\sigma_{\mathrm{m}}$, strain $\varepsilon_{\mathrm{m}}$, and elastic modulus $E_{\mathrm{t}}$ measured at $23{ }^{\circ} \mathrm{C}$ were tabulated in Table 2. For the unmodified epoxy system, the modulus amounted to $3230 \mathrm{MPa}$, and the tensile strength was 95.0 MPa. Later, with the addition of block copolymers to the epoxy, the modulus and tensile strength were decreased with an increase in particle content. This was because of the presence of soft blocks in the block copolymer $\left(E_{\mathrm{D} 51 \mathrm{~N}}=\right.$ $245 \mathrm{MPa}, \sigma_{\mathrm{m}}=7 \mathrm{MPa}$ ). Due to this, BCP's plasticize the whole network leading to a decrease in modulus and strength at relative higher $w t \%$. Later, with the addition of CSR to the epoxy, modulus and tensile strength also decreased with an increase in particle content, but this decrease was not as pronounced as for BCP's. It clearly indicates that the rubber core of

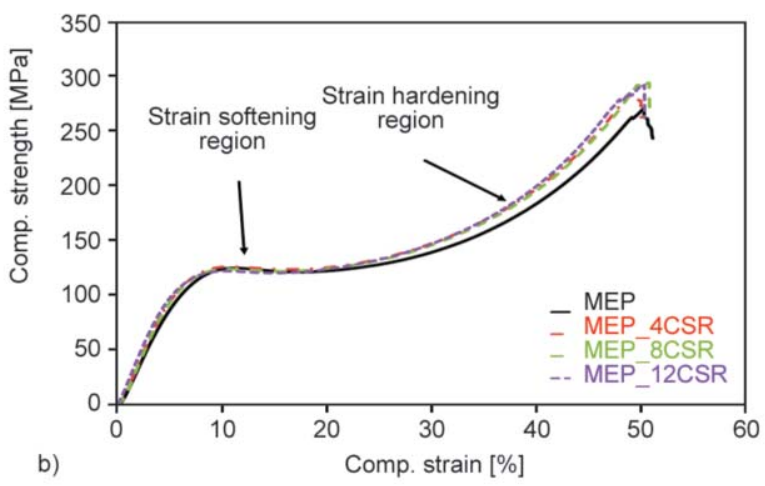

Figure 3. Compressive true stress vs. strain diagram of the unmodified and modified epoxy systems at different wt $\%$ (a) BCP modified, (b) CSR modified. 
Table 2. Tensile properties amine cured unmodified epoxy system and amine cured epoxy system modified with different modifiers at $23^{\circ} \mathrm{C}$.

\begin{tabular}{|l|c|c|c|c|c|}
\hline \multicolumn{1}{|c|}{ Systems } & $\begin{array}{c}\boldsymbol{E}_{\mathbf{t}} \\
{[\mathbf{M P a}]}\end{array}$ & $\begin{array}{c}\boldsymbol{\sigma}_{\mathbf{m}} \\
{[\mathbf{M P a}]}\end{array}$ & $\begin{array}{c}\boldsymbol{\varepsilon}_{\mathbf{m}} \\
{[\mathbf{\%}]}\end{array}$ & $\begin{array}{c}\boldsymbol{K}_{\mathbf{I c}} \\
{\left[\mathbf{M P a} \cdot \mathbf{m}^{\mathbf{1} / 2}\right]}\end{array}$ & $\begin{array}{c}\boldsymbol{G}_{\mathbf{I c}} \\
{\left[\mathbf{k J} / \mathbf{m}^{2}\right]}\end{array}$ \\
\hline EP & $2950( \pm 75.8)$ & $84.0( \pm 0.7)$ & $6.3( \pm 0.2)$ & $0.57( \pm 0.04)$ & $0.10( \pm 0.03)$ \\
\hline MEP & $3230( \pm 18.7)$ & $95.0( \pm 0.4)$ & $7.0( \pm 0.1)$ & $0.55( \pm 0.08)$ & $0.08( \pm 0.03)$ \\
\hline MEP_2BCP & $3120( \pm 28.1)$ & $90.1( \pm 0.3)$ & $6.8( \pm 0.2)$ & $0.85( \pm 0.05)$ & $0.20( \pm 0.02)$ \\
\hline MEP_4BCP & $3020( \pm 24.1)$ & $85.2( \pm 0.6)$ & $6.6( \pm 0.3)$ & $1.09( \pm 0.06)$ & $0.36( \pm 0.04)$ \\
\hline MEP_6BCP & $2920( \pm 33.0)$ & $82.2( \pm 0.5)$ & $6.6( \pm 0.2)$ & $1.11( \pm 0.02)$ & $0.38( \pm 0.05)$ \\
\hline MEP_8BCP & $2870( \pm 29.4)$ & $82.0( \pm 0.4)$ & $6.4( \pm 0.4)$ & $1.36( \pm 0.05)$ & $0.56( \pm 0.04)$ \\
\hline MEP_10BCP & $2855( \pm 38.2)$ & $81.0( \pm 0.9)$ & $6.4( \pm 0.3)$ & $1.41( \pm 0.02)$ & $0.61( \pm 0.05)$ \\
\hline MEP_12BCP & $2720( \pm 40.5)$ & $80.0( \pm 0.6)$ & $6.3( \pm 0.3)$ & $1.43( \pm 0.07)$ & $0.64( \pm 0.08)$ \\
\hline MEP_2CSR & $3190( \pm 12.0)$ & $92.1( \pm 0.3)$ & $6.8( \pm 0.1)$ & $0.84( \pm 0.08)$ & $0.19( \pm 0.04)$ \\
\hline MEP_4CSR & $3150( \pm 14.4)$ & $90.3( \pm 0.8)$ & $6.8( \pm 0.3)$ & $1.05( \pm 0.05)$ & $0.30( \pm 0.02)$ \\
\hline MEP_6 CSR & $3110( \pm 27.8)$ & $86.0( \pm 0.5)$ & $6.8( \pm 0.1)$ & $1.19( \pm 0.06)$ & $0.41( \pm 0.04)$ \\
\hline MEP_8CSR & $3090( \pm 40.5)$ & $86.0( \pm 0.5)$ & $6.8( \pm 0.1)$ & $1.29( \pm 0.05)$ & $0.48( \pm 0.05)$ \\
\hline MEP_10CSR & $3050( \pm 57.0)$ & $85.0( \pm 1.9)$ & $6.6( \pm 0.3)$ & $1.40( \pm 0.05)$ & $0.55( \pm 0.04)$ \\
\hline MEP_12CSR & $3020( \pm 34.6)$ & $84.0( \pm 0.5)$ & $6.5( \pm 0.3)$ & $1.43( \pm 0.07)$ & $0.57( \pm 0.05)$ \\
\hline MEP_1BCP_1CSR & $3100( \pm 58.2)$ & $91.3( \pm 1.5)$ & $6.7( \pm 0.3)$ & $1.01( \pm 0.01)$ & $0.29( \pm 0.01)$ \\
\hline MEP_2BCP_2CSR & $3050( \pm 61.0)$ & $89.0( \pm 1.3)$ & $6.4( \pm 0.2)$ & $1.15( \pm 0.03)$ & $0.39( \pm 0.02)$ \\
\hline MEP_3BCP_3CSR & $2920( \pm 7.21)$ & $84.4( \pm 0.6)$ & $6.0( \pm 0.4)$ & $1.31( \pm 0.05)$ & $0.52( \pm 0.04)$ \\
\hline
\end{tabular}

CSR was stiffer than that of conventional CSR's. Moreover, this was supported by the CSR (MX170) TDS, which claims to maintain the flexural modulus even at higher loadings [33]. For the addition of $2 \mathrm{wt} \%$ of the particle content, the values were observed to be 3190 and $92.1 \mathrm{MPa}$, respectively. Then, they decreased further with higher $w t \%$, until for $12 \mathrm{wt} \%$, modulus and strength reached 3020 and $84 \mathrm{MPa}$ only. This trend was due to the presence of the rubber particles which were having relatively lower modulus when compared to the unmodified epoxy system. Later, with the addition of $3 \mathrm{wt} \%$ of each BCP's and CSR particles to the epoxy, modulus, and tensile strength at $23{ }^{\circ} \mathrm{C}$ were reduced to 2920 and $84.4 \mathrm{MPa}$, respectively.

\subsection{Fracture properties}

The fracture toughness, $K_{\mathrm{Ic}}$, and fracture energy, $G_{\mathrm{Ic}}$, values of the amine cured unmodified epoxy system, and BCP modified epoxy systems are listed in Table 2. The fracture toughness and fracture energy of the unmodified epoxy were determined as $0.55 \mathrm{MPa} \cdot \mathrm{m}^{1 / 2}$ and $0.08 \mathrm{~kJ} / \mathrm{m}^{2}$, respectively. By the addition of block copolymers, these properties increased gradually to $1.43 \mathrm{MPa} \cdot \mathrm{m}^{1 / 2}$ and $0.64 \mathrm{~kJ} / \mathrm{m}^{2}$ (e.g. for $12 \mathrm{wt} \% \mathrm{BCP}$ ). This corresponds to an increase of 160 and $700 \%$, respectively, compared to the unmodified epoxy. It is in line with fracture toughness values reported in the product technical data sheet [41]. The gains in the values of $G_{\text {Ic }}$ and $K_{\text {Ic }}$ by the addition of the $\mathrm{BCP}$ were found to be almost linear. By the addition of CSR particles, these properties were also linearly increased to $1.43 \mathrm{MPa} \cdot \mathrm{m}^{1 / 2}$ and $0.57 \mathrm{~kJ} / \mathrm{m}^{2}$ (for $12 \mathrm{wt} \% \mathrm{CSR}$ ), which is a very similar improvement as for BCP. By a simultaneous addition of BCP's and CSR particles, the properties were increased gradually to $1.01 \mathrm{MPa} \cdot \mathrm{m}^{1 / 2}$ and $0.29 \mathrm{~kJ} / \mathrm{m}^{2}$ (for $2 \mathrm{wt} \%$ of each of the two particles). By a simultaneous addition of $6 \mathrm{wt} \%$ of the two, the properties further increased to $1.31 \mathrm{MPa} \cdot \mathrm{m}^{1 / 2}$ and $0.52 \mathrm{~kJ} / \mathrm{m}^{2}$. These were about 138 and $550 \%$ increments in the toughness and energy values when compared to the unmodified epoxy system.

\subsection{Toughening mechanisms}

The morphologies of the BCP and CSR modified epoxy systems were observed using AFM. Spherical micelles were observed on the surface of BCP modified systems, whereas uniformly distributed CSR particles were seen in the epoxy matrix for CSR modified systems as shown in Figure 4. Comprehensive fractographic studies were performed on the broken surfaces by using scanning electron microscopy (SEM). It was expected to find reasons especially for the improvement of fracture toughness and the bonding quality between the epoxy matrix and the filler material. Several mechanisms were identified that were responsible for the increase in 

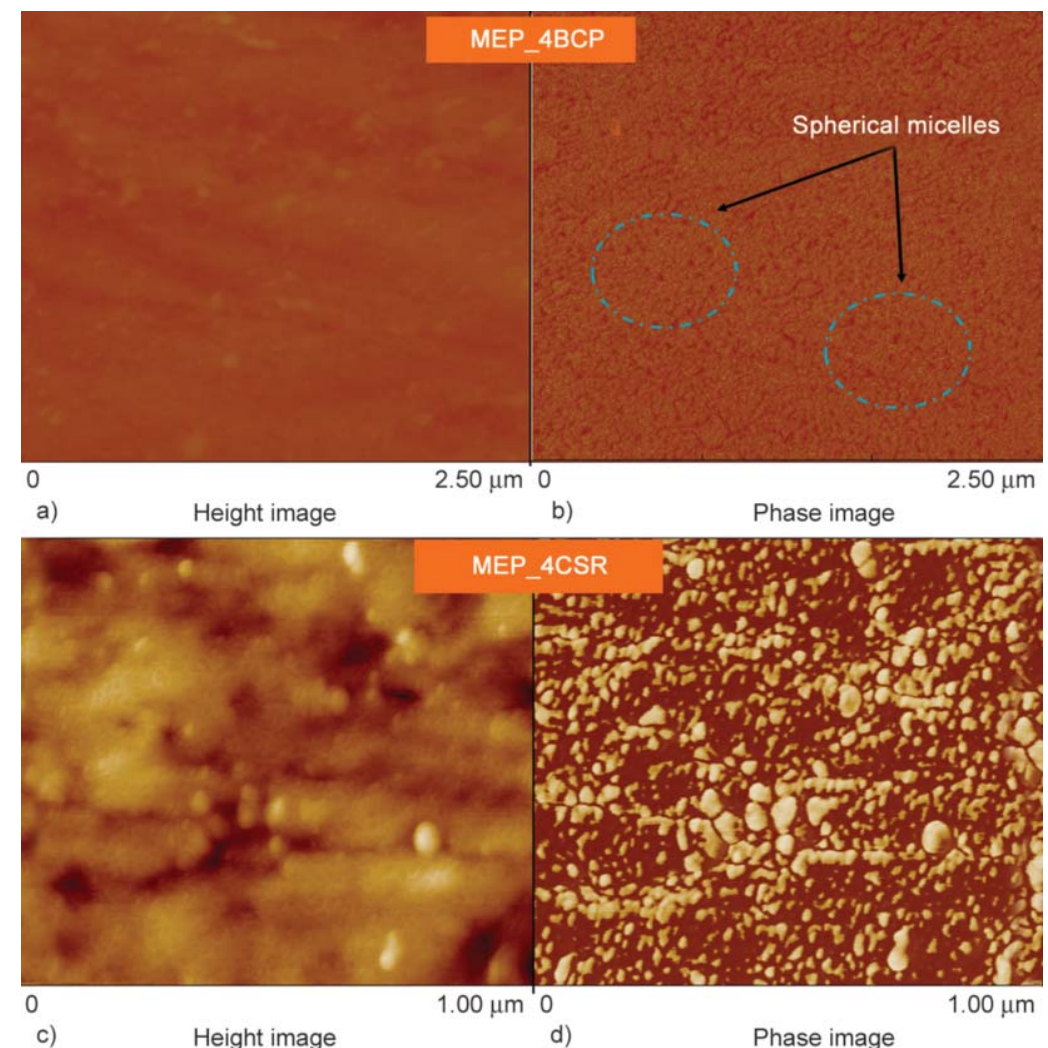

Figure 4. AFM height and phase images of MEP_4BCP and MEP_4CSR systems. (a) AFM height image of MEP_4BCP system, (b) AFM phase image MEP_4BCP system, (c) AFM height image of MEP_4CSR system, (d) AFM phase image of MEP_4CSR system

fracture toughness and they will be discussed in the following sections accordingly.

The fractured surface of the amine cured unmodified epoxy appeared to be smooth, without any traces of plastic deformation. This is usually seen in all types
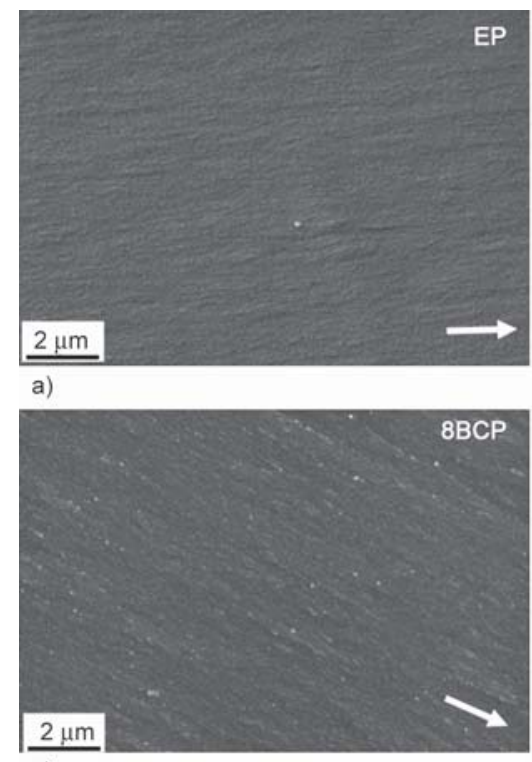

c) of unmodified brittle epoxies due to the absence of any filler materials that promote plastic deformation or other effects. The addition of BCP increased the fracture surface roughness, which was composed of river lines and sites of matrix tearing, indicating en-

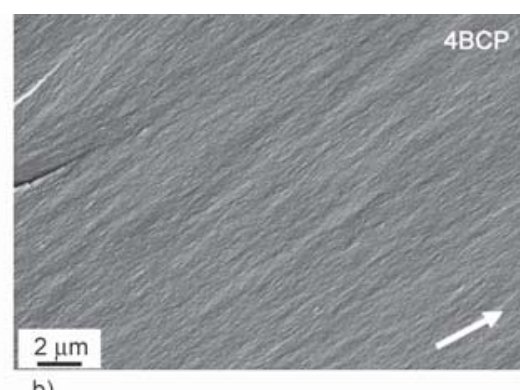

b)

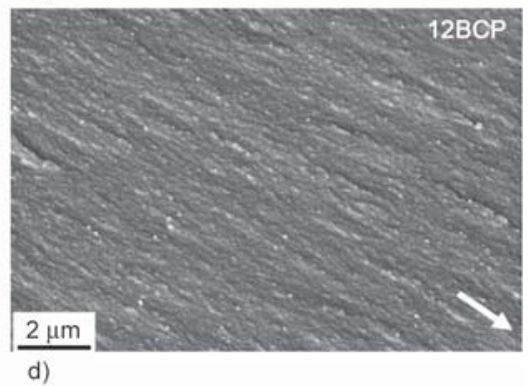

Figure 5. SEM micrographs of the fracture surface of the unmodified and BCP modified amine cured epoxy, taken in the vicinity of the tip of the pre-crack at $23^{\circ} \mathrm{C}$. The white arrow indicates the direction of crack propagation. (a) EP, (b) EP_4BCP, (c) EP_8BCP and (d) EP_12BCP. 


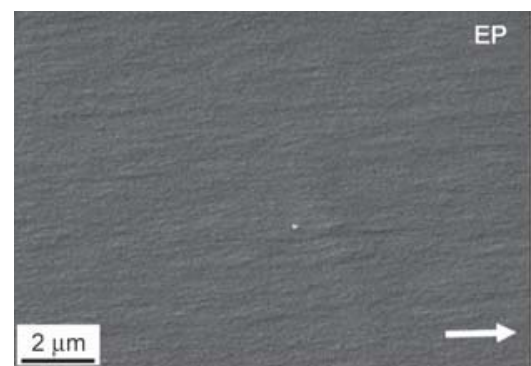

a)

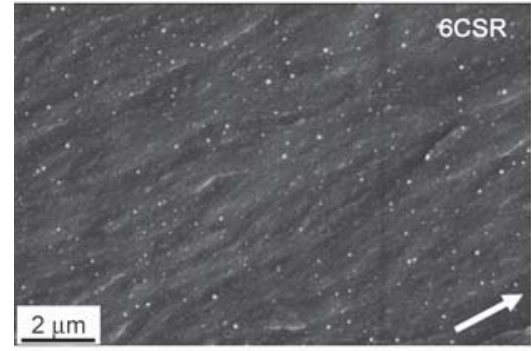

c)

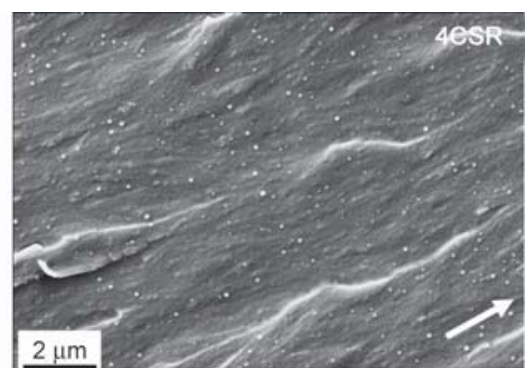

b)

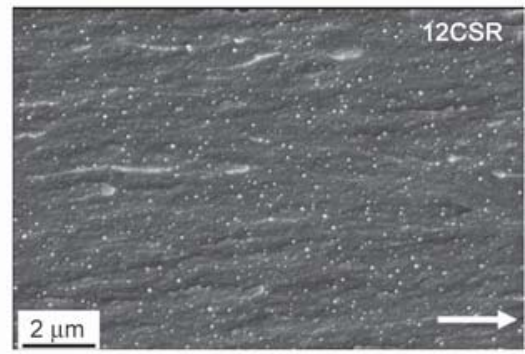

d)

Figure 6. SEM micrographs of the fracture surface of the unmodified and CSR modified amine cured epoxy, taken in the vicinity of the tip of the pre-crack at $23^{\circ} \mathrm{C}$. The white arrow indicates the direction of crack propagation. (a) EP, (b) EP_4CSR, (c) EP_6CSR and (d) EP_12CSR

hanced plastic deformation. This can be observed for the 4, 8, and $12 \mathrm{wt} \%$ BCP samples in Figure 5. Figure $5 \mathrm{~b}$ shows that the fracture surface of $\mathrm{BCP}$ modified systems was already rough at the nanometer scale, with many small nodule-like protrusions. It should be noted that the cavities and nodule like protrusions were not artifacts of the sputtering process used prior to the SEM imaging because they were not observed on the coated unmodified epoxy, and the presence of the nano-cavities and protrusions was independent of the coating material used. Furthermore, small-scale matrix tearing was observed on the fracture surfaces of the BCP modified epoxies for all concentrations of BCP's. These features indicate the enhanced plastic deformation of the epoxies.

Based on the SEM images of the fracture surfaces described above, certain toughening mechanisms involved in the BCP modified amine cured epoxies with different morphologies can be proposed. The filler particles can induce shear yielding in the matrix by building up a change in the stress state. This may result in the formation of nano-voids, nano-cavities and debonding effects in the process zone at the crack tip vicinity [42]. For the BCP modified epoxy, the toughening mechanisms were the cavitation of the latter and the plastic deformation of the epoxy. With the addition of CSR particles, the roughness of the surface was also increased, indicating that plastic deformation of the matrix occurred. At higher magnifications, the fractured surface of the CT specimens showed cavitation of rubber particles, followed by void formation see Figure $6 \mathrm{~b}-6 \mathrm{~d}$. The average diameter of the rubber particles was measured to be in the range of 100 to $150 \mathrm{~nm}$. A little increase in the diameters was observed for the voids formed by the cavitation of the particles. This means that plastic void growth took place around the particles during the deformation process.

From the micrographs, it can also be noted that the dispersion of the particles was uniform, meaning that only hardly any agglomerates were observed. Again, the major toughening mechanisms were cavitation of rubber particles, followed by void formation and shear yielding of the matrix see Figure 7.

\subsection{Plastic zone size}

The plain strain dimension of the plastic zone size can be quantified by Irwin's model, using Equation (4) [29] and assuming that the zone was circular and the crack occurs in the matrix. $K_{\text {Ic }}$ is the fracture toughness and $\sigma_{\mathrm{yt}}$ is the tensile true yield stress of the bulk polymer. In this way, a plastic zone radius of $2.13 \mu \mathrm{m}$ could be calculated for the MEP_H system using Equation (4), while a maximum plastic zone size of $17 \mu \mathrm{m}$ was determined for the MEP_12BCP. All other modified systems had a plastic zone size between these two extremes:

$r_{\mathrm{p}}=\frac{1}{6 \pi}\left(\frac{K_{\mathrm{Ic}}}{\sigma_{\mathrm{yt}}}\right)^{2}$ 


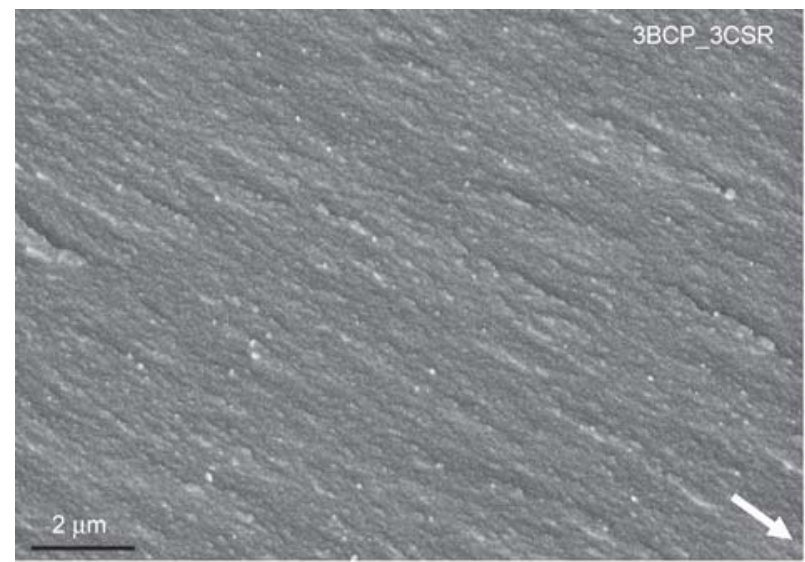

a)

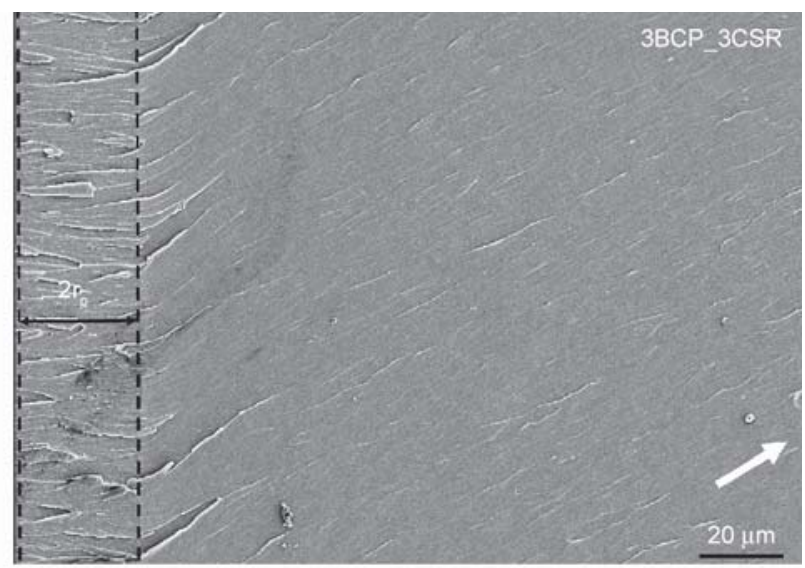

b)

Figure 7. (a) SEM micrographs of the fracture surface. (b) The fracture surface of MEP_3BCP_3CSR system showing the crack arrest region associated with plastic zone size $r_{\mathrm{p}}$. White arrows are representing the crack propagation direction.

The plastic zone was considerably larger than the radius of the BCP or CSR nanoparticles (Figure 8b). Therefore, these particles lie within the plastic zone and favor matrix toughening by events such as cavitation, plastic void growth (for $\mathrm{BCP}$ ), crack pinning, and crack deflection, compelling the material to dissipate more energy before failure. The plastic zone size radius from Irwin's model prediction and experimental measurement are listed in Table 3 along with surface roughness values of fractured samples. It can be observed that Irwin's model over predicted the radius which was also supported by other researchers $[29,43,44]$.

The reason for this over-prediction is due to the fact that Irwin's model assumes that only shear yielding as the deformation mechanism is dominant in the processing zone. Figure $8 \mathrm{a}$ shows different modified systems and reference systems. In the first step the strength of reference bis-F based epoxy system
Table 3. Plastic zone size values (measured and predicted) and surface roughness values of fractured samples.

\begin{tabular}{|l|c|c|c|}
\hline \multicolumn{1}{|c|}{ Series } & $\begin{array}{c}\text { PZS } \\
\text { measured } \\
{[\boldsymbol{\mu \mathbf { m } ]}}\end{array}$ & $\begin{array}{c}\text { PZS } \\
\text { predicted } \\
{[\boldsymbol{\mu \mathbf { m } ]}}\end{array}$ & $\begin{array}{c}\text { Surface } \\
\text { roughness } \\
{[\boldsymbol{\mu \mathbf { m } ]}}\end{array}$ \\
\hline MEP_H & $\mathrm{X}$ & 2.13 & 0.158 \\
\hline MEP_2BCP & 2.90 & 3.10 & 0.169 \\
\hline MEP_4BCP & 4.12 & 4.72 & 0.182 \\
\hline MEP_6BCP & 7.20 & 8.70 & 0.195 \\
\hline MEP_8BCP & 8.51 & 9.70 & 0.210 \\
\hline MEP_10BCP & 11.24 & 14.60 & 0.218 \\
\hline MEP_12BCP & 12.56 & 16.10 & 0.240 \\
\hline MEP_2CSR & 3.25 & 4.42 & 0.172 \\
\hline MEP_4CSR & 3.90 & 7.20 & 0.185 \\
\hline MEP_6CSR & 6.20 & 10.20 & 0.198 \\
\hline MEP_8CSR & 8.50 & 12.10 & 0.225 \\
\hline MEP_10CSR & 11.67 & 14.40 & 0.230 \\
\hline MEP_12CSR & 12.54 & 15.40 & 0.245 \\
\hline MEP_1BCP_1CSR & 3.10 & 6.50 & 0.175 \\
\hline MEP_2BCP_2CSR & 5.60 & 8.90 & 0.185 \\
\hline MEP_3BCP_3CSR & 7.50 & 12.80 & 0.220 \\
\hline
\end{tabular}

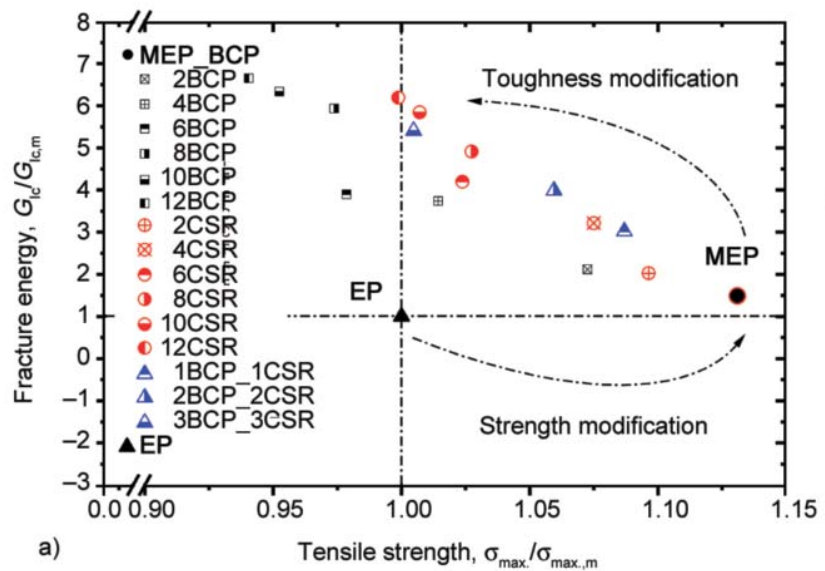

Figure 8. (a) Graph showing the relation between the normalized fracture energy and normalized tensile strength for different modified systems in comparison to the EP system. (b) Fracture toughness and critical energy release rate of different toughened epoxy systems as a function of plastic zone radius $\left(r_{\mathrm{p}}\right)$. 
is increased to $\sim 15 \%$ by adding $7 \mathrm{wt} \%$ of LME 10169 . Later toughness modifiers were incorporated in the modified reference system resulting in an increase in fracture energy with a decline in tensile strength of the system. But when compared with ref. bis-F system a few materials still possess superior tensile, fracture mechanical and thermo-mechanical properties.

\section{Modeling studies}

\subsection{Rubber particle toughening}

The toughening effects due to the mechanisms mentioned above can be estimated by using an analytical model developed by Hsieh et al. [45], based on a previous Huang and Kinloch model [46, 47]. This model was used by several researchers $[14,35,40]$ and results revealed that this analytical model could accurately predict the fracture energy of particle modified epoxies with toughening mechanisms of void growth and shear band yielding.

Huang et al. [46] proposed that the toughening increment of fracture energy can be written as shown in Equation (5):

$G_{\mathrm{cm}}=G_{\mathrm{cu}}+\Psi$

where $G_{\mathrm{cu}}$ is the fracture energy of the unmodified epoxy polymer and $\Psi$ represents the overall toughening contribution provided by the presence of the particulate phase. The model directly addressed the toughening mechanisms observed from the experimental observations and assumed that the mechanisms are mutually exclusive to each other. The overall toughening contribution was divided into the relative toughening contributions, see Equation (6):

$\Psi_{\mathrm{EP}}=\Delta G_{\mathrm{s}}+\Delta G_{\mathrm{v}}$

(i) Localized shear band yielding, $\Delta G_{\mathrm{s}}$, (ii) plastic void growth of the epoxy polymer, $\Delta G_{\mathrm{v}}$. The fracture energy contribution from plastic shear band yielding, $\Delta G_{\mathrm{s}}$ initiated by the particles is referred to the size of the plastic zone from [45] as shown in Equation (7):

$\Delta G_{\mathrm{s}}=0.5 V_{\mathrm{fp}} \sigma_{\mathrm{ycu}} \gamma_{\mathrm{fu}} F^{\prime}\left(r_{\mathrm{y}}\right)$

where $V_{\mathrm{fp}}$ is the particle volume fraction, $\sigma_{\mathrm{ycu}}$ is the plane strain compressive true yield stress, $\gamma_{\mathrm{fu}}$ is the fracture strain for the unmodified epoxy, and $F^{\prime}\left(r_{\mathrm{y}}\right)$ is given by Equation (8):

$$
F^{\prime}\left(r_{\mathrm{y}}\right)=r_{\mathrm{y}}\left[\left(\frac{4 \pi}{3 V_{\mathrm{fp}}}\right)^{1 / 3}\left(1-\frac{r_{\mathrm{p}}}{r_{\mathrm{y}}}\right)^{3}-\frac{40}{35}\left(\frac{r_{\mathrm{p}}}{r_{\mathrm{y}}}-1\right)^{3 / 2} \frac{r_{\mathrm{p}}}{r_{\mathrm{y}}}\left(\frac{7}{5}-\frac{r_{\mathrm{p}}}{r_{\mathrm{y}}}\right)-2\left(1-\frac{r_{\mathrm{p}}}{r_{\mathrm{y}}}\right)^{2}+\frac{16}{35}\right]
$$

where $r_{\mathrm{p}}$ is the particle radius, $r_{\mathrm{y}}$ is the increased plastic zone size due to the stress concentrations in the epoxy matrix. It is defined by Equation (9):

$r_{\mathrm{y}}=K_{\mathrm{vm}}^{2}\left(1+\frac{\mu_{\mathrm{m}}}{3^{1 / 2}}\right)^{2} r_{\mathrm{pzu}}$

where $K_{\mathrm{vm}}$ is the maximum stress concentration for the von Mises stresses around the particle and $\mu_{\mathrm{m}}$ is a material constant that allows for the pressure-dependency of the yield stress. The value of $\mu_{\mathrm{m}}$ is a material constant relating to the hydrostatic dependence of yielding, and was measured to be between 0.175 and 0.225 for rubber-modified epoxy polymers [48]. The value of $K_{\mathrm{vm}}$ is dependent on the volume fraction of particles and was calculated numerically by Huang and Kinloch [46]. The value of $K_{\mathrm{vm}}$ varies with volume fraction, and a simple linear relationship can be obtained for soft modifiers by Equation (10):

$K_{\mathrm{vm}}=3.9337 V_{\mathrm{fp}}+2.1126$

Similarly, for hard (rigid) modifiers, the value of $K_{\mathrm{vm}}$ is given by Equation (11):

$K_{\mathrm{vm}}=0.918 V_{\mathrm{fp}}+2.1126$

The Irwin prediction of plain strain plastic zone radius for the unmodified epoxy at fracture was calculated by [49] Equation (12):

$r_{\mathrm{pzu}}=\frac{1}{6 \pi}\left(\frac{K_{\mathrm{Ic}}}{\sigma_{\mathrm{yt}}}\right)^{2}$

where $K_{\mathrm{Ic}}$ is the fracture toughness and $\sigma_{\mathrm{yt}}$ is the tensile true yield strength of the unmodified epoxy polymer.

The contribution of $\Delta G_{\mathrm{v}}$ through plastic void growth mechanism can be calculated using Equation (13) [47]:

$\Delta G_{\mathrm{v}}=\left(1+\frac{\mu_{\mathrm{m}}}{3^{1 / 2}}\right)^{2}\left(V_{\mathrm{fv}}-V_{\mathrm{fp}}\right) \sigma_{\mathrm{yt}} r_{\mathrm{pzu}} K_{\mathrm{vm}}^{2}$

where $\mu_{\mathrm{m}}$ is material constant as discussed above, $V_{\mathrm{fp}}$ is the particle volume fraction and $V_{\mathrm{fv}}$ is the volume fraction of voids. The term $V_{\mathrm{fv}}-V_{\mathrm{fp}}$ can either be determined experimentally from SEM pictures or predicted from the Equations (14) and (15):

$r_{\mathrm{fv}}=\left(1+\gamma_{\mathrm{fu}}\right) r_{\mathrm{p}}$ 
$V_{\mathrm{fv}}-V_{\mathrm{fp}}=V_{\mathrm{fp}} \frac{r_{\mathrm{fv}}^{3}-r_{\mathrm{p}}^{3}}{r_{\mathrm{p}}^{3}}$

where $r_{\mathrm{fv}}$ is the void radius, and $\gamma_{\mathrm{fu}}$ is the failure strain. The measured values of $V_{\mathrm{fv}}$ were found by several authors $[21,50]$ to be in good agreement with the values measured from the fracture surfaces, within a certain experimental error. It is worth noting that the contribution from shear band yielding and void growth dominates the total energy contribution at various volume fractions, as well as at different test temperatures [47]. No traces of rubber bridging mechanisms were found in the current systems; hence a rubber bridging term can be neglected while calculating the fracture energy contribution. Therefore, the total predicted fracture energy is given by Equation (16):

$G_{\mathrm{cm}}=G_{\mathrm{cu}}+\Psi_{\mathrm{EP}}$

where $\Psi_{\mathrm{EP}}$ is the summation of energy contribution by shear yielding and void growth, using the values of $\Delta G_{\mathrm{s}}$ and $\Delta G_{\mathrm{v}}$ from Equations (7) and (13) respectively. Equation (5) can then be written as shown in Equation (17):

$$
\begin{aligned}
G_{\mathrm{cm}} & =G_{\mathrm{cu}}+0.5 V_{\mathrm{fp}} \sigma_{\mathrm{ycu}} \gamma_{\mathrm{fu}} F^{\prime}\left(r_{\mathrm{y}}\right)+ \\
& +\left(1+\frac{\mu_{\mathrm{m}}}{3^{1 / 2}}\right)^{2}\left(V_{\mathrm{fv}}-V_{\mathrm{fp}}\right) \sigma_{\mathrm{yt}} r_{\mathrm{pzu}} K_{\mathrm{vm}}^{2}
\end{aligned}
$$

The main toughening mechanisms for BCP modified epoxy polymers were identified as plastic void growth initiated by the cavitation of the BCP particles and localized shear yielding. The main toughening mechanisms for CSR particle modified epoxy polymers were identified as localized shear yielding and plastic void growth initiated by the cavitation of the
CSR particles. The individual contributions for each toughening mechanism can be predicted and compared with the experimental results. The parameters used and calculations done in the modeling are listed in Table 4 and Table 5 respectively. The contribution in fracture energy from shear yielding was calculated by Equation (7) and plastic void growth by Equation (13). From cryo-fracture specimens of the bulk samples, the radius of the block copolymer phase in epoxy was measured as $10 \mathrm{~nm}$. It was difficult to accurately determine the volume fraction of particles that undergo cavitation experimentally. Finite element studies by Guild et al. [51] suggest that all rubbery particles in the fracture plane should cavitate, and analysis of the fracture surfaces confirms this. Moreover, it was assumed that all the cavities would not undergo the maximum extent of plastic void growth, i.e. only up to a void radius equal to $\left(1+\gamma_{\mathrm{fu}}\right) r_{\mathrm{p}}$, due to a local reduction in stress near a void. This means, the particles which cavitate and undergo full plastic void growth vary between an upper bound of $100 \%$ and a lower bound of $14.3 \%$ [45, 51].

However, in the current work, fractographic examination revealed that $\mathrm{BCP}$ particles did not undergo full cavitation. Therefore, only $15 \%$ of the BCP particles were assumed to cavitate fully. Similarly, the CSR particles used were stiff as compared to conventional polysiloxane based CSR particles, and this effect was evident from the mechanical properties of the MEP_CSR system, as discussed from the fractographic examinations. Also here, it can be concluded that only a few CSR particles were cavitated (the assumption was $10 \%$ of CSR particles). For EP_BCP and EP_CSR systems, a good agreement was found between experimentally measured and predicted values of fracture energy $G_{\text {Ic }}$ see Figure 9.

Table 4. Parameters and values for the modeling studies to predict the fracture energy for modified epoxy systems at $23^{\circ} \mathrm{C}$.

\begin{tabular}{|l|l|cc|}
\hline \multicolumn{1}{|c|}{ Name } & \multicolumn{1}{|c|}{ Variable } & Value \\
\hline Radius of the particles & $r_{\mathrm{p}} \quad[\mathrm{nm}]$ & Table 5 \\
\hline Void radius & $r_{\mathrm{fv}}[\mathrm{nm}]$ & Table 5 \\
\hline$V_{\mathrm{fv}}-V_{\mathrm{fp}}$ & $V_{\mathrm{fv},} V_{\mathrm{fp}}$ & Table 5 \\
\hline Poisson's ratio of the unmodified epoxy & $\mathrm{v}$ & 0.35 & {$[52]$} \\
\hline Plane-strain compressive yield true stress & $\sigma_{\mathrm{yc}}[\mathrm{MPa}]$ & 108 & (Present study) \\
\hline Plane-strain compressive fracture true strain & $\gamma_{\mathrm{f}}$ & 0.98 & (Present study) \\
\hline Uniaxial tensile yield true stress & $\sigma_{\mathrm{yt}}[\mathrm{MPa}]$ & 95 & (Present study) \\
\hline Pressure-dependent yield stress parameter & $\mu_{\mathrm{m}}$ & 0.2 & [47] \\
\hline Fracture energy & $G_{\mathrm{Ic}}\left[\mathrm{J} / \mathrm{m}^{2}\right]$ & 85 & (Present study) \\
\hline Critical stress intensity factor & $K_{\mathrm{Ic}}\left[\mathrm{MPa} \cdot \mathrm{m}^{1 / 2}\right]$ & 0.55 & (Present study) \\
\hline von Mises stress concentration factor & $K_{\mathrm{vm}}$ & $K_{\mathrm{vm}}=3.9337 V_{\mathrm{fp}}+2.1126$ & {$[46]$} \\
\hline
\end{tabular}


Table 5. Corresponding volume $\%$, mean radius, void radius and $\left(V_{\mathrm{fv}}-V_{\mathrm{fp}}\right)$ values of anhydride based BCP and CSR modified epoxy systems respectively.

\begin{tabular}{|c|c|c|c|c|}
\hline $\begin{array}{c}\text { BCP } \\
{[w t \%]}\end{array}$ & $\begin{array}{c}\text { BCP } \\
{[\mathrm{vol} \%]}\end{array}$ & $\begin{array}{c}\text { Radius } \\
{[\mathrm{nm}]}\end{array}$ & $\begin{array}{l}\text { Void radius } \\
\text { [nm] }\end{array}$ & $V_{\mathrm{fv}}-V_{\mathrm{fp}}$ \\
\hline 2 & 2.1 & 10 & 19.8 & 0.145 \\
\hline 4 & 4.2 & 10 & 19.8 & 0.288 \\
\hline 6 & 6.3 & 10 & 19.8 & 0.432 \\
\hline 8 & 8.5 & 10 & 19.8 & 0.575 \\
\hline 10 & 10.6 & 10 & 19.8 & 0.718 \\
\hline 12 & 12.7 & 10 & 19.8 & 0.860 \\
\hline $\begin{array}{c}\text { CSR } \\
{[w t \%]}\end{array}$ & $\begin{array}{c}\text { CSR } \\
\text { [vol\%] }\end{array}$ & $\begin{array}{c}\text { Radius } \\
{[\mathrm{nm}]}\end{array}$ & $\begin{array}{l}\text { Void radius } \\
\text { [nm] }\end{array}$ & $V_{\mathrm{fv}}-V_{\mathrm{fp}}$ \\
\hline 2 & 2.1 & 50 & 99 & 0.139 \\
\hline 4 & 4.1 & 50 & 99 & 0.278 \\
\hline 6 & 6.2 & 50 & 99 & 0.417 \\
\hline 8 & 8.2 & 50 & 99 & 0.556 \\
\hline 10 & 10.3 & 50 & 99 & 0.695 \\
\hline 12 & 12.3 & 50 & 99 & 0.833 \\
\hline
\end{tabular}

\section{Conclusions}

A high strength epoxy/amine system was modified with the addition of different toughening agents mainly BCP, CSR, and a combination of them to investigate their mechanical and thermo-mechanical properties as well as their fracture mechanical behavior. The BCP's have no detrimental effect on the glass transition temperature of the composites. The tensile tests showed that the strength and modulus decreased upon an increase in the filler concentration, because of the soft block content of PbuA present in BCP. At the same time, the fracture toughness $K_{\mathrm{Ic}}$ and the fracture energy $G_{\text {Ic }}$ were increased by a factor of 2 and 8 , respectively. The toughening mechanisms responsible for this improvement were identified as shear yielding, nano-cavitation of spherical particles, followed by void growth. For the amine cured epoxy

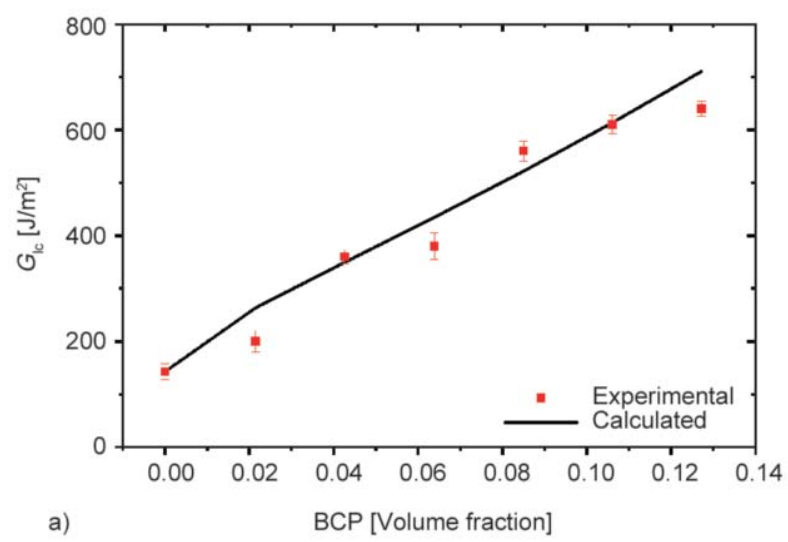

modified with core-shell rubber (CSR) particles, the glass transition temperature either remains the same or increased due to an addition of bisphenol-A based masterbatch of CSR particles. Tensile tests showed that the strength and modulus were decreased due to the presence of rubber particles, which were having lower modulus when compared to the unmodified epoxy system, but this decreasing rate was less when compared with block copolymer particles. But at the same time, the fracture toughness $K_{\text {Ic }}$ and the fracture energy $G_{\text {Ic }}$ were increased by an average factor of 2.5 and 7 , respectively. The principle toughening mechanisms observed were cavitation of rubber particles, shear yielding of the matrix. Fracture energy was predicted by using the modified Huang-Kinloch fracture energy model, which assumes that the total fracture energy of the modified systems consists of fracture energy of an unmodified epoxy sample, energy contribution from shear band yielding, energy contribution from void growth mechanism and energy contribution from rubber bridging mechanisms. For the BCP modified amine-based system the total fracture energy contribution considered from shear band yielding and cavitation followed by void growth and the predicted results were in good agreement with the experimental values. Similarly, for CSR particles modified systems, the main contribution comes from shear band yielding and relatively low contribution from debonding and void growth (which was $10 \%$ for amine-based systems).

\section{Acknowledgements}

The authors gratefully acknowledge the provision of Nanostrength products by Arkema, KaneAce MX products by Kaneka Belgium N.V. and the resin systems by Huntsman Corp., Switzerland. Furthermore, the authors thank Dr. Sergiy Grishchuk for fruitful discussions.

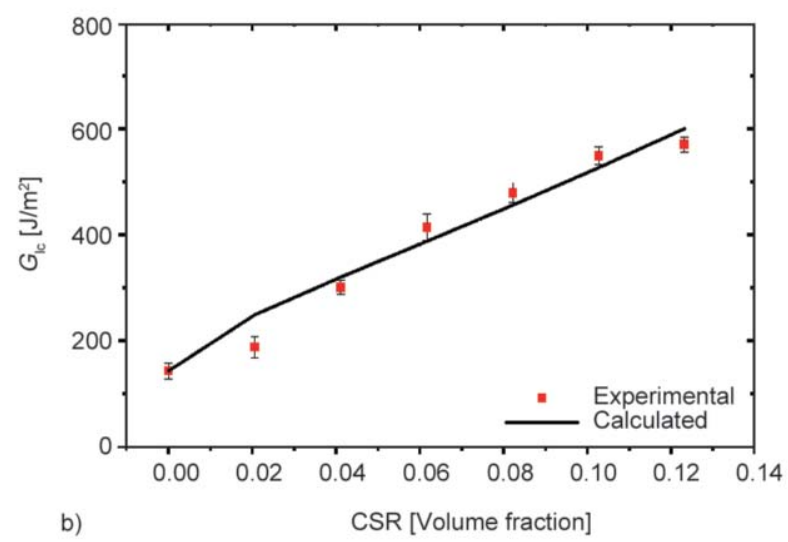

Figure 9. Fracture energy vs volume fraction for the (a) BCP and (b) CSR modified MEP system at $23^{\circ} \mathrm{C}$. Data points were experimental data, the line represents theoretical prediction. 


\section{References}

[1] Grishchuk S., Schmitt S., Vorster O. C., Karger-Kocsis J.: Structure and properties of amine-hardened epoxy/ benzoxazine hybrids: Effect of epoxy resin functionality. Journal of Applied Polymer Science, 124, 2824 2837 (2012).

https://doi.org/10.1002/app.35302

[2] Karger-Kocsis J., Friedrich K.: Microstructure-related fracture toughness and fatigue crack growth behaviour in toughened, anhydride-cured epoxy resins. Composites Science and Technology, 48, 263-272 (1993). https://doi.org/10.1016/0266-3538(93)90143-5

[3] Ratna D.: Handbook of thermoset resins. Smithers, Shawbury (2009).

[4] Rezaifard A. H., Hodd K. A., Tod D. A., Barton J. M.: Toughening epoxy resins with poly(methyl methacrylate)-grafter-natural rubber, and its use in adhesive formulations. International Journal of Adhesion and Adhesives, 14, 153-159 (1994).

https://doi.org/10.1016/0143-7496(94)90011-6

[5] Pearson R. A., Yee A. F.: Toughening mechanisms in thermoplastic-modified epoxies. 1. Modification using poly(phenylene oxide). Polymer, 34, 3658-3670 (1993). https://doi.org/10.1016/0032-3861(93)90051-B

[6] Bucknall C. B., Gilbert A. H.: Toughening tetrafunctional epoxy resins using polyetherimide. Polymer, 30, 213-217 (1989). https://doi.org/10.1016/0032-3861(89)90107-9

[7] Luo Y., Zhang M., Dang G., Li Y., An X., Chen C., Yi $\mathrm{X}$.: Toughening of epoxy resin by poly(ether ether ketone) with pendant fluorocarbon groups. Journal of Applied Polymer Science, 122, 1758-1765 (2011). https://doi.org/10.1002/app.34292

[8] Bucknall C. B., Gomez C. M., Quintard I.: Phase separation from solutions of poly(ether sulfone) in epoxy resins. Polymer, 35, 353-359 (1994).

https://doi.org/10.1016/0032-3861(94)90703-X

[9] Yi X-S.: Development of multifunctional composites for aerospace application. in 'Multifunctionality of polymer composites' (Friedrich K., Breuer U.) Oxford, Elsevier, 367-418 (2015).

https://doi.org/10.1016/B978-0-323-26434-1.00011-8

[10] Karger-Kocsis J.: Self-healing properties of epoxy resins with poly( $\varepsilon$-caprolactone) healing agent. Polymer Bulletin, 73, 3081-3093 (2016). https://doi.org/10.1007/s00289-016-1642-2

[11] Liu R., Wang J., Li J., Jian X.: An investigation of epoxy/ thermoplastic blends based on addition of a novel copoly (aryl ether nitrile) containing phthalazinone and biphenyl moieties. Polymer International, 64, 1786-1793 (2015). https://doi.org/10.1002/pi.4980

[12] Raghava S. R.: Role of matrix-particle interface adhesion on fracture toughness of dual phase epoxy-polyethersulfone blend. Journal of Polymer Science Part B: Polymer Physics, 25, 1017-1031 (1987). https://doi.org/10.1002/polb.1987.090250504
[13] Di Liello V., Martuscelli E., Musto P., Ragosta G., Scarinzi G.: Toughening of highly crosslinked epoxy resins by reactive blending with bisphenol A polycarbonate. II. Yield and fracture behavior. Journal of Polymer Science Part B: Polymer Physics, 32, 409-419 (1994). https://doi.org/10.1002/polb.1994.090320302

[14] Giannakopoulos G., Masania K., Taylor A. C.: Toughening of epoxy using core-shell particles. Journal of Materials Science, 46, 327-338 (2010).

https://doi.org/10.1007/s10853-010-4816-6

[15] Barsotti R. L.: Nanostrength block copolymers for epoxy toughening. in 'Thermoset Resin Formulators Association Annual Meeting 2008, Chicago, USA' 7-9 (2008).

[16] Pearson R., Bacigalupo L., Liang Y., Marouf B., Oldak R.: Plastic zone size - fracture toughness correlations in rubber-modified epoxies. in 'Proceedings of the $31^{\text {st }}$ Annual Meeting of the Adhesion Society, Austin, USA' 27-29 (2008).

[17] Kishi H., Kunimitsu Y., Nakashima Y., Imade J., Oshita S., Morishita Y., Asada M.: Relationship between the mechanical properties of epoxy/PMMA- $b$-PNBA- $b$ PMMA block copolymer blends and their three-dimensional nanostructures. Express Polymer Letters, 11, 765777 (2017).

https://doi.org/10.3144/expresspolymlett.2017.74

[18] Bajpai A., Wetzel B.: Effect of different types of block copolymers on morphology, mechanical properties, and fracture mechanisms of bisphenol-F based epoxy system. Journal of Composites Science, 3, 68-80 (2019). https://doi.org/10.3390/jcs3030068

[19] Bajpai A., Alapati A., Klingler A., Wetzel B.: Tensile properties, fracture mechanics properties and toughening mechanisms of epoxy systems modified with soft block copolymers, rigid $\mathrm{TiO}_{2}$ nanoparticles and their hybrids. Journal of Composites Science, 2, 72-87 (2018). https://doi.org/10.3390/jcs2040072

[20] Wetzel B., Rosso P., Haupert F., Friedrich K.: Epoxy nanocomposites - Fracture and toughening mechanisms. Engineering Fracture Mechanics, 73, 2375-2398 (2006). https://doi.org/10.1016/j.engfracmech.2006.05.018

[21] Hsieh T. H., Kinloch A. J., Masania K., Taylor A. C., Sprenger S.: The mechanisms and mechanics of the toughening of epoxy polymers modified with silica nanoparticles. Polymer, 51, 6284-6294 (2010). https://doi.org/10.1016/j.polymer.2010.10.048

[22] Azimi H. R., Pearson R., Hertzberg R.: Role of crack tip shielding mechanisms in fatigue of hybrid epoxy composites containing rubber and solid glass spheres. Journal of Applied Polymer Science, 58, 449-463 (1995). https://doi.org/10.1002/app.1995.070580223

[23] Maxwell D., Young R. J., Kinloch A. J.: Hybrid particulate-filled epoxy-polymers. Journal of Materials Science Letters, 3, 9-12 (1984). https://doi.org/10.1007/BF00720061 
[24] Carolan D., Ivankovic A., Kinloch A. J., Sprenger S., Taylor A. C.: Toughening of epoxy-based hybrid nanocomposites. Polymer, 97, 179-190 (2016).

https://doi.org/10.1016/j.polymer.2016.05.007

[25] Bajpai A., Carlotti S.: The effect of hybridized carbon nanotubes, silica nanoparticles, and core-shell rubber on tensile, fracture mechanics and electrical properties of epoxy nanocomposites. Nanomaterials, 9, $1057-$ 1067 (2019).

https://doi.org/10.3390/nano9071057

[26] Wang Y. T., Wang C. S., Yin H. Y., Wang L. L., Xie H. F., Cheng R. S.: Carboxyl-terminated butadiene-acrylonitrile-toughened epoxy/carboxyl-modified carbon nanotube nanocomposites: Thermal and mechanical properties. Express Polymer Letters, 6, 719-728 (2012). https://doi.org/10.3144/expresspolymlett.2012.77

[27] Szebényi G., Tóth L., Karger-Kocsis J.: Effect of an ionic liquid on the flexural and fracture mechanical properties of EP/MWCNT nanocomposites. Materials Science Forum, 885, 19-24 (2017).

https://doi.org/10.4028/www.scientific.net/MSF.885.19

[28] Bajpai A., Alapati A. K., Wetzel B.: Toughening and mechanical properties of epoxy modified with block copolymers and MWCNTs. Procedia Structural Integrity, 2, 104-111 (2016).

https://doi.org/10.1016/j.prostr.2016.06.014

[29] Klingler A., Bajpai A., Wetzel B.: The effect of block copolymer and core-shell rubber hybrid toughening on morphology and fracture of epoxy-based fibre reinforced composites. Engineering Fracture Mechanics, 203, 81-101 (2018).

https://doi.org/10.1016/j.engfracmech.2018.06.044

[30] Bajpai A., Wetzel B., Klingler A., Friedrich K.: Mechanical properties and fracture behavior of high-performance epoxy nanocomposites modified with block polymer and core-shell rubber particles. Journal of Applied Polymer Science, 136, 48471/1-48471/14 (2019). https://doi.org/10.1002/app.48471

[31] Hexion: Product specifications and technical data sheet for the EPON862. Hexion Inc., Lansing (2005).

[32] Huntsman: Technical data sheet for developmental resin LME10169. Huntsman Advance Materials GmbH, Basel (2015).

[33] Kaneka: Technical data sheet- Kane ace trade mark MX-170. Kaneka Belgium, Brussels (2015).

[34] Xiao K., Ye L., Kwok Y. S.: Effects of pre-cracking methods on fracture behaviour of an araldite-F epoxy and its rubber-modified systems. Journal of Materials Science, 33, 2831-2836 (1998). https://doi.org/10.1023/A:1017533819817

[35] Chen J., Taylor A. C.: Epoxy modified with triblock copolymers: Morphology, mechanical properties and fracture mechanisms. Journal of Materials Science, 47, 4546-4560 (2012).

https://doi.org/10.1007/s10853-012-6313-6
[36] Ritzenthaler S., Girard-Reydet E., Pascault J. P.: Influence of epoxy hardener on miscibility of blends of poly (methyl methacrylate) and epoxy networks. Polymer, 41, 6375-6386 (2000). https://doi.org/10.1016/S0032-3861(99)00817-4

[37] Ritzenthaler S., Court F., David L., Girard-Reydet E., Leibler L., Pascault J. P.: ABC triblock copolymers/ epoxy-diamine blends. 1. Keys to achieve nanostructured thermosets. Macromolecules, 35, 6245-6254 (2002).

https://doi.org/10.1021/ma0121868

[38] Williams J. G., Ford H.: Stress-strain relationships for some unreinforced plastics. Journal of Mechanical Engineering Science, 6, 405-417 (1964).

https://doi.org/10.1243\%2FJMES JOUR_1964 $006 \quad 055 \quad 02$

[39] Haward R. N.: The physics of glassy polymers. Applied Science Publishers, London (1973).

https://doi.org/10.1007/978-94-010-2355-9

[40] Chong H. M., Taylor A. C.: The microstructure and fracture performance of styrene-butadiene-methylmethacrylate block copolymer-modified epoxy polymers. Journal of Materials Science, 48, 6762-6777 (2013).

https://doi.org/10.1007/s10853-013-7481-8

[41] Arkema: Technical data sheet - Nanostrength ${ }^{\circledR}$ epoxy application. Arkema, Paris (2013).

[42] Bagheri R., Pearson R. A.: Role of particle cavitation in rubber-toughened epoxies: 1. Microvoid toughening. Polymer, 37, 4529-4538 (1996). https://doi.org/10.1016/0032-3861(96)00295-9

[43] Dittanet P., Pearson R. A.: Effect of bimodal particle size distributions on the toughening mechanisms in silica nanoparticle filled epoxy resin. Polymer, 54, 18321845 (2013).

https://doi.org/10.1016/j.polymer.2012.12.059

[44] Quan D., Pearson R. A., Ivankovic A.: Interaction of toughening mechanisms in ternary nanocomposites. Polymer Composites, 39, 3482-3496 (2018). https://doi.org/10.1002/pc. 24368

[45] Hsieh T. H., Kinloch A. J., Masania K., Lee J. S., Taylor A. C., Sprenger S.: The toughness of epoxy polymers and fibre composites modified with rubber microparticles and silica nanoparticles. Journal of Materials Science, 45, 1193-1210 (2010). https://doi.org/10.1007/s10853-009-4064-9

[46] Huang Y., Kinloch A. J.: Modelling of the toughening mechanisms in rubber-modified epoxy polymers. Part I - Finite element analysis studies. Journal of Material Science, 24, 2753-2762 (1992). https://doi.org/10.1007/BF00540702

[47] Huang Y., Kinloch A. J.: Modelling of the toughening mechanisms in rubber-modified epoxy polymers. Part II - A quantitative description of the microstructure fracture property relationships. Journal of Materials Science, 27, 2763-2769 (1992). https://doi.org/10.1007/BF00540703 
[48] Sultan J. N., McGarry F.: Effect of rubber particle size on deformation mechanisms in glassy epoxy. Polymer Engineering and Science, 13, 29-34 (1973). https://doi.org/10.1002/pen.760130105

[49] Kinloch A. J., Young R. J.: Fracture behaviour of polymers. Elsevier, New York (1983).

https://doi.org/10.1007/978-94-017-1594-2

[50] Chen J., Kinloch A. J., Sprenger S., Taylor A. C.: The mechanical properties and toughening mechanisms of an epoxy polymer modified with polysiloxane-based core-shell particles. Polymer, 54, 4276-4289 (2013). https://doi.org/10.1016/j.polymer.2013.06.009
[51] Guild F. J., Kinloch A. J., Taylor A. C.: The debonding of nanoparticles in toughened adhesives. in ' $37^{\text {th }}$ Annual Meeting of the Adhesion Society, San Diego, USA' p3 (2014).

[52] Kinloch A. J.: Adhesion and adhesives. Springer, Heidelberg (1987).

https://doi.org/10.1007/978-94-015-7764-9 